\title{
RESEARCH
}

\section{Total Hip Arthroplasty in Young Adults with Stickler Connective Tissue Disorder: Review of Literature and Case}

\author{
Drew W. Taylor', Jennifer E. Taylor ${ }^{2}$, Kyle C. Bohm², Matthew P. MacDonald', Allan E. Gross \\ 'Division of Orthopaedic Surgery, Mount Sinai Hospital, Toronto, Ontario, Canada \\ ${ }^{2}$ University of Michigan, Ann Arbor, Michigan, United States
}

\begin{abstract}
Connective tissue disorders such as Stickler syndrome cause the premature development of musculoskeletal disease resembling spondyloepiphyseal dysplasia, in some cases requiring surgical intervention for premature development of osteoarthritis. Total hip arthroplasty is a routine procedure regarded as highly successful in maintaining mobility in elderly patients. When hip replacement is required in the young, unique challenges are presented to the surgeon including efforts to maximize the life of the first prosthesis while also considering that multiple revisions will likely be necessary. A 17 year old male patient presented with a connective tissue disorder, exhibiting symptoms of Stickler syndrome. The patient suffered from acute episodes of pain and dysfunction including mechanical clicking and occasional locking, originally seeking orthopaedic assessment at 14 years old. Total hip arthroplasty was performed after the patient's femoral growth plate had fused radiologically and is presented as an option to treat the multifaceted abnormal hip joint caused by Sticklers syndrome. In this way, hip mobility and functionality can be vastly improved in young adults with debilitating congenital connective tissue disorders.
\end{abstract}

\section{Introduction}

Multiple congenital connective tissue disorders present unique challenges for orthopaedic surgeons regarding the premature development of musculoskeletal abnormalities and deficiencies. One of the most common autosomal dominant connective tissue dysplasias is Stickler syndrome, affecting around 1 in 10,000 births. $^{1-3}$ Stickler syndrome was first described as a disorder of retinal degeneration, hearing loss, orofacial abnormalities, and premature osteoarthritis by Stickler et al. in $1965 .{ }^{4}$ The hereditary arthroophthalmopathy disorder is known to be caused by mutations in procollagen genes of type II and XI, specifically mutations in the COL2A1 (Stickler syndrome type I), COL11A1 (Stickler syndrome type II), and COL11A2 (Stickler syndrome type III) genes. ${ }^{5-16}$ More recently a new autosomal recessive form has been described involving a mutation in the COL9A1 gene. ${ }^{17}$ Additional genetic heterogeneity is likely, since linkage to type II and XI has been excluded in some families with Stickler syndrome. ${ }^{13}$ Diagnosing Stickler syndrome is highly dependent on phenotypic observations as opposed to solely relying on genetic screening. ${ }^{18}$

Regardless of the locus of mutation there are multiple deformities that are common with the condition, including craniofacial abnormalities such as cleft palate, flattened cheek bones (malar hypoplasia), deep set eyes (enophthalmos), and an undershot lower jaw (retrognathia). ${ }^{19-21}$ The combination of cleft palate, glossoptosis, and micrognathia, referred to as Pierre-Robin sequence, can be present and result in respiratory obstruction. This is of significance if anaesthetic management is required for surgery. ${ }^{17 ; 22}$ In addition, there is a high incidence of ocular and auditory degeneration with age. ${ }^{19 ; 23-31}$ Despite the widely accepted age-related progression of ocular and auditory impairment in Stickler syndrome, one report depicted the postnatal remission of these symptoms. ${ }^{32}$ There have been no known reports indicating the improvement of orthopaedic conditions. Skeletal alterations resemble mild spondyloepiphyseal dysplasia, affecting the development of the spine and ends of bones from birth, and are present in almost all patients, ${ }^{33-36}$ with a high incidence of vertebral abnormalities including scoliosis ${ }^{37}$ and osteoporosis. ${ }^{38}$ Radiologically, metaphyseal broadening of long bones is apparent, causing joint restriction and premature development of osteoarthritis. Joint instability manifested through joint laxity and hypermobility contributes to premature development of joint disease, and osteoarthritis is frequently diagnosed in the second decade. ${ }^{4 ; 03 ; 33 ; 39}$ Abnormalities of the hip are extremely common in patients with Stickler and include coxa 


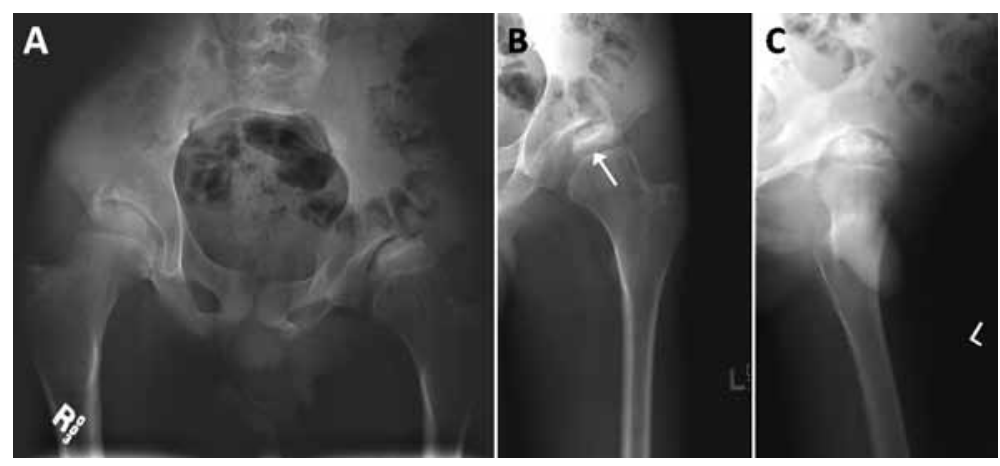

Figure 1. X-rays taken 3 years prior to surgery when the patient was 14 years of age. Bi-lateral coronal image (A) along with left hip coronal (B) and sagittal (C) images. The white arrow points to the unfused epiphyseal plate. Although degenerative changes are visible and pain was present, surgery was delayed until the growth plates fused. The long skinny bones and abnormal pelvic orientation typical of Stickler syndrome are apparent.

valga, protrusion of the acetabulum, chondrolysis, slipped epiphysis, and Perthes disease.

\section{Case Report}

A 17 year old male patient presented with pain in the left hip. He had first sought orthopaedic assessment as early as age fourteen, complaining of acute episodes of pain and dysfunction including mechanical clicking and occasional locking. He presented with laxity when externally rotated (70 degrees), but had fixed left hip abduction and flexion, having no internal rotation (0 degrees). Passive flexion of 30 degrees was observed on the left side, but with assistance flexion to 80 degrees was possible. The patient was able to ambulate for periods of 5 to 10 minutes but had to occasionally use analgesics and walked with an antalgic gait favoring the left hip. At the age of 14, x-rays revealed that all of his epiphyses were still open and more growth was expected (Fig.1). It was decided that left total hip arthroplasty was required to correct the dysplasia, however with epiphyseal plates open, surgery was delayed and follow-up scheduled on an annual basis.

At a height of $186 \mathrm{~cm}$, he was between the 90th and 97th percentiles for his age, while his weight of $57.3 \mathrm{~kg}$ placed him between the 10th and 25th percentiles for his age. Despite being extremely tall and extremely thin, physical examination revealed symmetrical pulses of good volume. The only notable finding was a soft systolic murmur at the lower left sternal border. Echocardiogram demonstrated
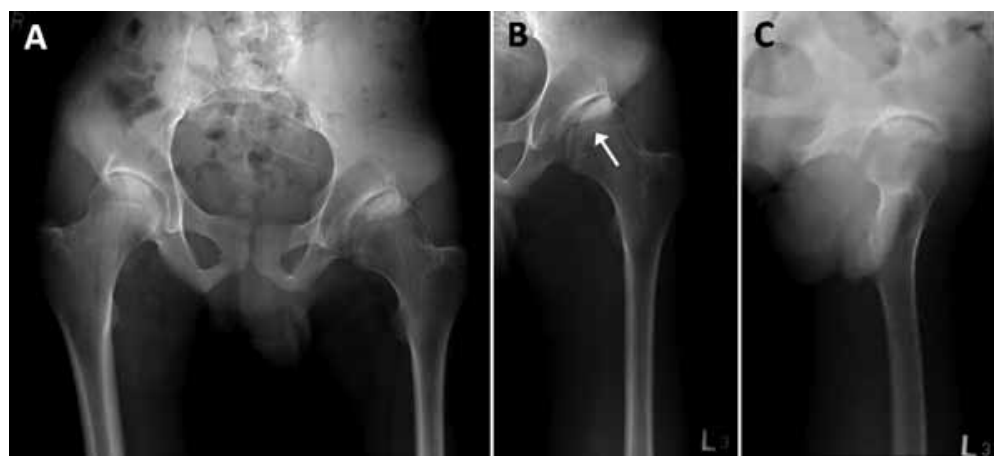

Figure 2. X-rays taken one month prior to surgery when the patient was 17 years of age. Bi-lateral coronal image (A) along with left hip coronal (B) and sagittal (C) images. The white arrow points to the now fused epiphyseal plate. Progression of degenerative changes is apparent and coincides with increased pain experienced by the patient. Note the severe pelvic tilt contributing to a large leg length discrepancy. 


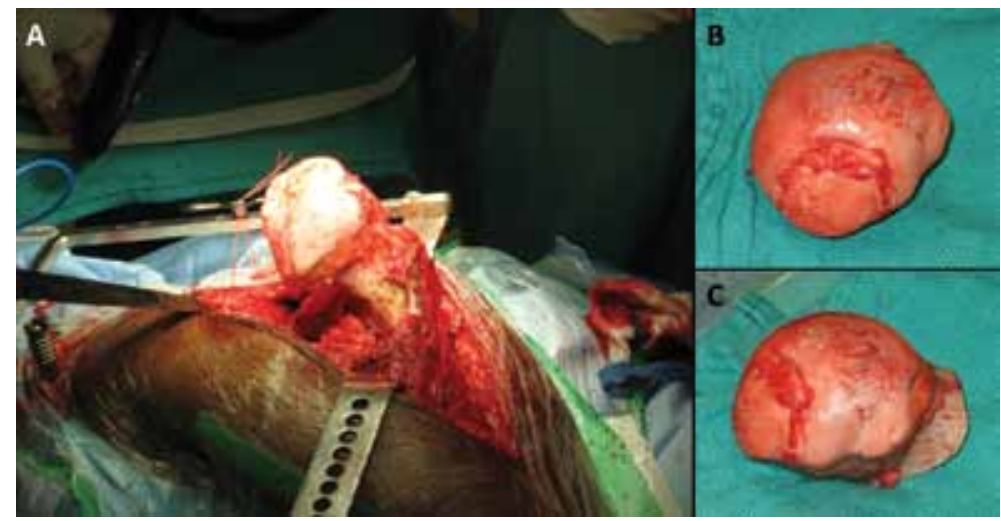

Figure 3. Intraoperative pictures including the proximal femur after trochlear slide osteotomy and dislocation of the femoral head (A). The degenerative changes and abnormal pathology are evident on the surface of the femoral head after removal (B,C). Articular cartilage appears osteoarthritic at only 17 years of age.

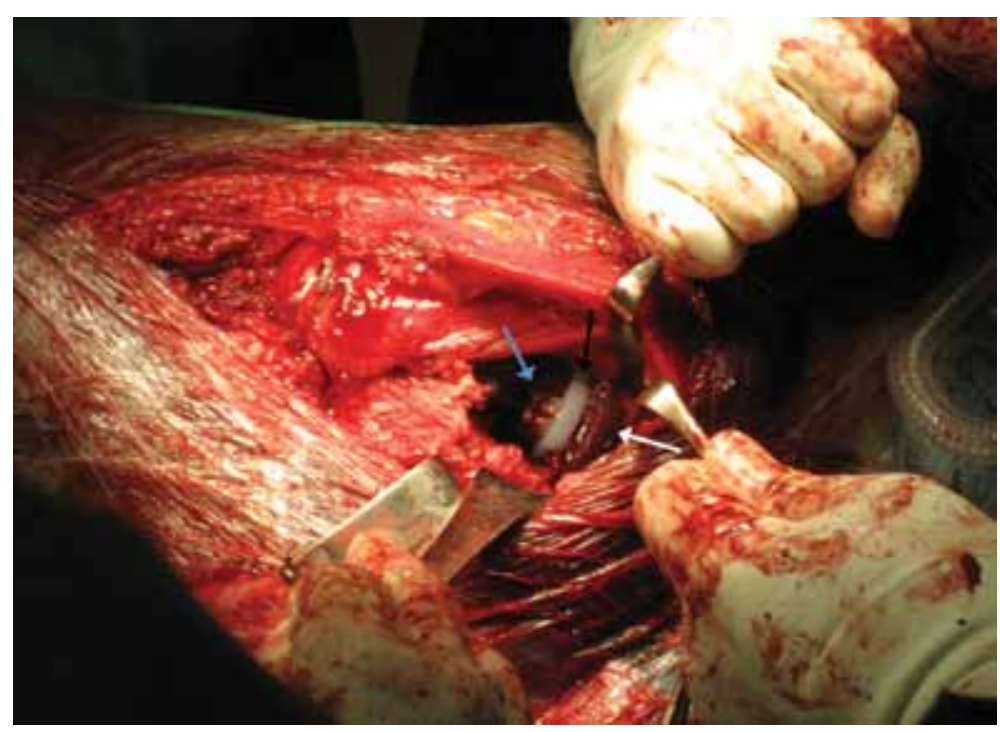

Figure 4. Intraoperative picture through lateral incision. The acetabular cup is depicted by a white arrow. The metal showing is the area not covered by the reamed acetabulum and will be the site of shelf graft construction using morselized bone. The black arrow points to the modular polyethylene liner. A blue arrow shows the head of the femoral device resting in place within the acetabular component.

Over the following years, follow-up x-rays confirmed multiple epiphyseal dysplasia. Internal rotation of the left hip remained zero, while external rotation showed a decrease to less than 30 degrees. Over two years after his initial visit, $\mathrm{x}$-rays confirmed that his growth plates had fused (Fig.2). A shallow acetabulum was evident on the left side in conjunction with osteoarthritis and avascular necrosis. The patient now walked with a significant limp, suffering from a $4 \mathrm{~cm}$ leg length discrepancy. Pain and discomfort were great and intervention was determined to be necessary to restore the ability to ambulate comfortably. After confirming epiphyseal fusion, surgery was scheduled for a total hip replacement.

\section{Materials and Methods \\ Operative Technique}

The degenerative changes observed radiologically were confirmed surgically; osteoarthritis was present on the femoral head (Fig.3). The acetabulum was very shallow and was remodeled through reaming. Chips and morselized bone from reaming were removed from the reamer heads and saved for later use. A $54 \mathrm{~mm}$ Zimmer $^{\mathrm{TM}}$ Modular Acetabular System was selected for implantation. The modular system consists of a metal shell, crosslinked polyethylene liner, and bone screws. Three bone screws were used to secure the metal shell while the polyethylene liner was snapped into place within the metal shell. Modular liners are uncemented and thus are far easier to remove if revision is expected. Seventy percent of the cup was covered by the bored acetabulum, so a graft of morselized bone was used to offset this discrepancy. A morselized bone autograft was used instead of a solid allograft for the shelf graft. Although it cannot be expected to initially provide ingrowth or stability, the morselized graft can undergo revascularization and remodeling over time. During incision closing, soft tissue is used to cover the morselized autograft to keep it in place during bone remodeling and vascularization.

Due to the avascular necrosis, combined with pelvic tilt and scoliosis, a large leg length discrepancy of $4 \mathrm{~cm}$ was noted, with the left side being longer. To correct this, a shortened neck was used in the femoral component, while also including a larger femoral head to help prevent dislocation. As Stickler syndrome had resulted in long, thin bones, consideration was also taken in selecting the size of the femoral stem. Again in an effort to make subsequent revisions easier, a relatively small stem size of $7.5 \mathrm{~mm}$ was implemented. The femoral component is similarly uncemented to allow for the preservation of bone stock when removing the device in the future. The implanted components can be seen intraoperatively in Figure 4. 


\section{Results}

Immediate post-operative $\mathrm{x}$-rays showed good placement of the prosthesis (Fig.5). Post-procedure, the patient's left leg had good dorsal pedis and posterior tibialis pulses and was neurovascularly intact. Management of the hip replacement included a diligent rehabilitation program. During the first week post-op, the patient was encouraged to begin range-of-motion ankle exercises and moving with a walker for 5 to 10 feet from the first day after surgery. Throughout the first week, aided walking was extended to 25 to 45 feet, and stair-climbing with crutches was introduced after day five. Strengthening and progressive ambulation remained the primary goal; this individual progressed to full weight bearing 8 weeks after surgery. Hip exercises were implemented to regain range of motion that was absent before surgery, but for the first 3 months the patient was advised not to bend his knee past 90 degrees to avoid dislocation and damage to the hip and device. Six weeks after the operation the patient was evaluated and found to have no pain and good range of motion. X-rays were taken after 2 months to confirm placement and fixation of the aetabular and femoral components and evaluate the success of the shelf autograft (Fig.6). The components appeared to be in place and fixated well.

\section{Discussion}

To our knowledge, there are no studies (case or series) that describe the unique challenges that are present in total hip arthroplasty of young patients with Stickler syndrome. Complications become of even greater concern when the patient is not an adult. There is not a great deal of information regarding the interactions between the acetabulum and femoral head during development and maturation, but it has been previously described that premature closure of the growth plate following trauma leads to subluxation of the femoral head. ${ }^{40}$ Despite these concerns, successful surgeries on many young adults for chronic arthritis ${ }^{41-43}$ or tumour resection $^{4-48}$ have been reported. When malignant disease is not of concern, in children and young adults it is very favorable to wait until the patient's growth plates have fused before continuing with planned hip arthroplasties. In cases like this, where the concern is a connective tissue disorder, waiting until growth plates have fused eliminates additional complications, although the patient may have to endure discomfort and pain during this time.

Rose et al. ${ }^{33}$ provided a study into the hip pathology present in patients with Stickler syndrome. When reviewing clinical data on 59 consecutive Stickler patients, 49 of the patients had radiographs suitable

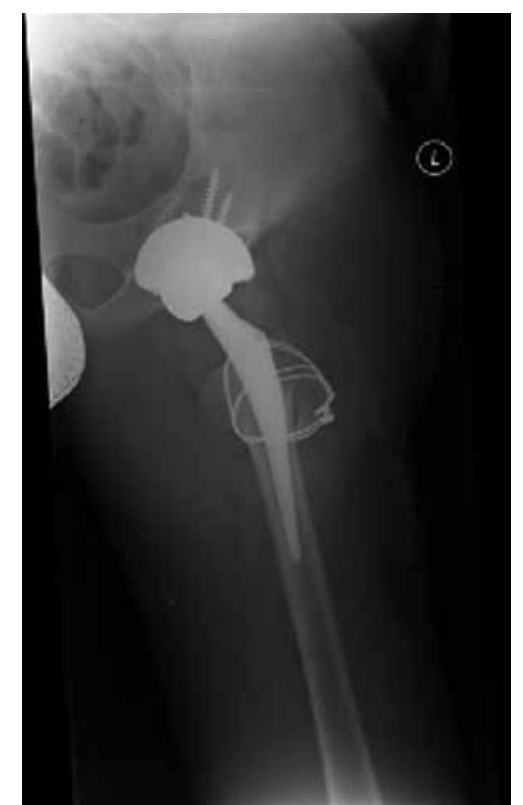

Figure 5. Immediate postoperative coronal $x$-ray of the left hip. Wires securing the greater trochanter after the trochlear slide osteotomy are present. The three bone screws fixating the acetabular component are also evident. The device appears to be in good position with the femoral head securely within the acetabulum.

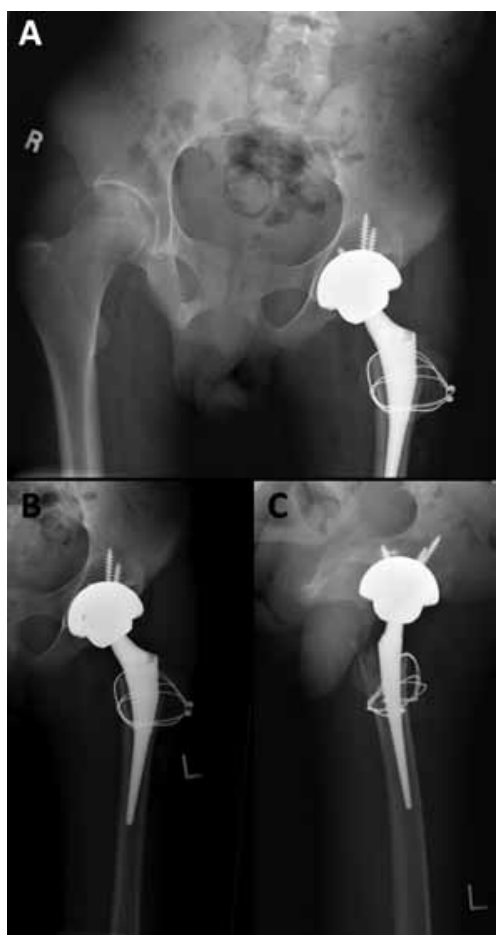

Figure 6. X-rays taken two months after surgery. Bilateral coronal image (A) along with left hip coronal (B) and sagittal (C) images. The components appear in place with good fixation. 
for evaluation. Osteoarthritis was present in 19 hips in 13 patients, all reporting hip pain, while smaller degenerative changes were found in 18 hips in an additional 13 patients, of which ten reported hip pain. Minor degenerative changes were present in children as young as thirteen, while osteoarthritis was described in patients as young as fifteen. Thirty-three percent of adults were found to have osteoarthritis of the hip. Of patients over five years of age, chronic hip pain was described by $63 \%$, including five of the 17 minors. In adults, $79 \%$ reported musculoskeletal pain, 20\% medically disabled from the pain. Protrusio acetabuli was present in $10 \%$ of the patients, detected as early as thirteen years of age. In addition, $28 \%$ of patients were found to have varus or valgus deformities of the femoral neck. Of the 38 adult patients, six had a history of femoral neck failure due to slipped capital femoral epiphysis, Legg-Perthes disease, or acute chondrolysis. They reported three of these patients had undergone total hip arthroplasty at the ages of 15,26 , and 29 , with an additional two who were planning for surgery, at the time aged 18 and 37. No surgical details, challenges, or outcomes were mentioned.

We present total hip arthroplasty as a viable treatment to alleviate pain and discomfort in the multifaceted abnormal hip joint inherent with connective tissue disorders such as Sticklers. In any young patient undergoing total hip replacement, the ultimate goal is to maximize the success of planned revisions. By selecting a femoral component with a narrow stem, bone stock can be preserved. Also, by not cementing the components and using a modular acetabular component, bone stock can further be preserved when removing the device. After surgical intervention, this young adult had the ability to ambulate without pain and can return to a relatively normal lifestyle.

\section{References}

1. Herrmann J, France TD, Spranger JW, et al. The Stickler syndrome (hereditary arthroophthalmopathy). Birth Defects Orig Artic Ser 1975;11:76-103.

2. Letts M, Kabir A, Davidson D. The spinal manifestations of Stickler's syndrome. Spine 1999;24:1260-1264.

3. Opitz JM, France T, Herrmann J, et al. The Stickler syndrome. N Engl J Med 1972;286:546-547.

4. Stickler GB, Belau PG, Farrell FJ, et al. Hereditary progressive arthro-ophthalmopathy. Mayo Clin Proc 1965;40:433-455.

5. Ahmad NN, McDonald-McGinn DM, Zackai EH, et al. A second mutation in the type II procollagen gene (COL2AI) causing Stickler syndrome (arthro-ophthalmopathy) is also a premature termination codon. Am J Hum Genet 1993;52:39-45.

6. Avcin T, Makitie O, Susic M, et al. Early-Onset osteoarthritis due to otospondylomegaepiphyseal dysplasia in a family with a novel splicing mutation of the COL11A2 gene. J Rheumatol 2008;35:920-926.

7. Donoso LA, Edwards AO, Frost AT, et al. Identification of a stop codon mutation in exon 2 of the collagen $2 \mathrm{~A} 1$ gene in a large stickler syndrome family. Am J Ophthalmol 2002;134:720-727.

8. Donoso LA, Edwards AO, Frost AT, et al. Clinical variability of Stickler syndrome: Role of exon 2 of the collagen COL2A1 gene. Surv Ophthalmol 2003;48:191-203.

9. Francomano CA, Liberfarb RM, Hirose T, et al. The Stickler syndrome: Evidence for close linkage to the structural gene for type II collagen. Genomics 1987;1:293-296.

10. Francomano CA, Liberfarb RM, Hirose $\mathrm{T}$, et al. The Stickler syndrome is closely linked to COL2A1, the structural gene for type II collagen. Pathol Immunopathol Res 1988;7:104106.

11. Knowlton RG, Weaver EJ, Struyk AF, et al. Genetic linkage analysis of hereditary arthro-ophthalmopathy (Stickler syndrome) and the type II procollagen gene. Am J Hum Genet 1989;45:681-688.

12. Liberfarb RM, Levy HP, Rose PS, et al. The Stickler syndrome: Genotype/phenotype correlation in 10 families with Stickler syndrome resulting from seven mutations in the type II collagen gene locus COL2A1. Genet Med 2003;5:21-27.

13. Martin S, Richards AJ, Yates JR, et al. Stickler syndrome: Further mutations in COL11A1 and evidence for additional locus heterogeneity. Eur J Hum Genet 1999;7:807-814.

14. Sirko-Osadsa DA, Murray MA, Scott JA, et al. Stickler syndrome without eye involvement is caused by mutations in COL11A2, the gene encoding the alpha2(XI) chain of type XI collagen. J Pediatr 1998;132:368-371.

15. van Steensel MA, Buma P, Waal Malefijt MC, et al. Oto- spondylomegaepiphyseal dysplasia (OSMED): Clinical description of three patients homozygous for a missense mutation in the COL11A2 gene. Am J Med Genet 1997;70:315-323.

16. Zlotogora J, Granat M, Knowlton RG. Prenatal exclusion of Stickler syndrome. Prenat Diagn 1994;14:145-147.

17. Van Camp G, Snoeckx RL, Hilgert N, et al. A new autosomal recessive form of Stickler syndrome is caused by a mutation in the COL9A1 gene. Am J Hum Genet 2006;79:449-457.

18. Rose PS, Levy HP, Johnston JJ. Proposed diagnostic criteria for stickler syndrome. Am J Hum Genet 2000;67:S56.

19. Liberfarb RM, Hirose T, Holmes LB. The Wagner-Stickler syndrome: a study of 22 families. J Pediatr 1981;99:394-399.

20. Liberfarb RM, Hirose T. The Wagner-Stickler syndrome. Birth Defects Orig Artic Ser 1982;18:525-538.

21. Saksena SS, Bixler D, Yu PI. Stickler syndrome: A cephalometric study of the face. J Craniofac Genet Dev Biol 1983;3:19-28.

22. Kucukyavuz Z, Ozkaynak O, Tuzuner AM, et al. Difficulties in anesthetic management of patients with micrognathia: Report of a patient with Stickler syndrome. Oral Surg Oral Med Oral Pathol Oral Radiol Endod 2006;102:e33-e36.

23. Ang A, Poulson AV, Goodburn SF, et al. Retinal detachment and prophylaxis in type 1 Stickler syndrome. Ophthalmology 2008;115:164-168.

24. Rabinowitz R, Gradstein L, Galil A, et al. The ocular manifestations of Weissenbacher-Zweymuller syndrome. Eye 2004;18:1258-1263.

25. Seery CM, Pruett RC, Liberfarb RM, et al. Distinctive cataract in the Stickler syndrome. Am J Ophthalmol 1990;110:143-148.

26. Snead MP, Yates JR, Williams R, et al. Stickler syndrome type 2 and linkage to the COL11A1 gene. Ann N Y Acad Sci 1996;785:331332.

27. Snead MP, Yates JR. Clinical and Molecular genetics of Stickler syndrome. J Med Genet 1999;36:353-359.

28. Admiraal RJ, Brunner HG, Dijkstra TL, et al. Hearing loss in the nonocular Stickler syndrome caused by a COL11A2 mutation. Laryngoscope 2000;110:457-461.

29. Admiraal RJ, Szymko YM, Griffith AJ, et al. Hearing impairment in Stickler syndrome. Adv Otorhinolaryngol. 2002;61:216-223.

30. Lewkonia RM. The arthropathy of hereditary arthroophthalmopathy (Stickler syndrome). J Rheumatol 1992;19:1271-1275.

31. Szymko-Bennett YM, Mastroianni MA, Shotland LI, et al. 
Auditory dysfunction in Stickler syndrome. Arch Otolaryngol Head Neck Surg 2001;127:1061-1068.

32. Fujiwaki T, Nishimura G, Ohashi H, et al. Postnatal remission of ocular, auditory, and somatic findings in Stickler syndrome. Pediatr Int 2004;46:605-608

33. Rose PS, Ahn NU, Levy HP, et al. The hip in Stickler syndrome. J Pediatr Orthop 2001;21:657-663.

34. Spallone A. Stickler's syndrome: A study of 12 families. Br J Ophthalmol 1987;71:504-509.

35. Spranger J. Spondyloepiphyseal dysplasias. Birth Defects Orig Artic Ser 1975;11:177-182.

36. Spranger J. The epiphyseal dysplasias. Clin Orthop Relat Res 1976;46-59.

37. Rose PS, Ahn NU, Levy HP, et al. Thoracolumbar spinal abnormalities in Stickler syndrome. Spine 2001;26:403-409.

38. Rudolph G, Kalpadakis P, Bettecken T, et al. Spondylo-ocular syndrome: A new entity with crystalline lens malformation, cataract, retinal detachment, osteoporosis, and platyspondyly. Am J Ophthalmol 2003;135:681-687.

39. Rai A, Wordsworth P, Coppock JS, et al. Hereditary arthroophthalmopathy (Stickler syndrome): A diagnosis to consider in familial premature osteoarthritis. Br J Rheumatol 1994;33:11751180.

40. Bucholz RW, Ezaki M, Ogden JA. Injury to the acetabular triradiate physeal cartilage. J Bone Joint Surg Am 1982;64:600609.

41. Kitsoulis PB, Stafilas KS, Siamopoulou A, et al. Total hip arthroplasty in children with juvenile chronic arthritis: Long-term results. J Pediatr Orthop 2006;26:8-12.

42. Ruddlesdin C, Ansell BM, Arden GP, et al. Total hip replacement in children with juvenile chronic arthritis. J Bone Joint Surg Br 1986;68:218-222.

43. Witt JD, Swann M, Ansell BM. Total hip replacement for juvenile chronic arthritis. J Bone Joint Surg Br 1991;73:770-773.

44. Carpenter EB. Resection of the proximal third of the femur for chondrosarcoma in a child: Replacement with a metallic prosthesis. Case report. J Bone Joint Surg Am 1979;61:628-630.

45. Carpenter EB. Resection of the proximal third of the femur for chondrosarcoma: Replacement with a metallic prosthesis. A note after fifteen years of follow-up. J Bone Joint Surg Am 1987;69:279281.

46. Donati D, Zavatta M, Gozzi E, et al. Modular prosthetic replacement of the proximal femur after resection of a bone tumour a long-term follow-up. J Bone Joint Surg Br 2001;83:11561160.

47. Donati D, Albisinni U, Zavatta $M$, et al. Long-term roentgenographic evaluation of proximal femur prosthesis after tumor resection. Chir Organi Mov 2004;89:191-203.

48. van KM, Grimer RJ, Carter SR, et al. Replacement of the hip in children with a tumor in the proximal part of the femur. J Bone Joint Surg Am 2008;90:785-795.

\section{cuadvertising}

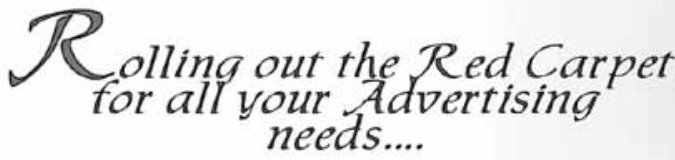

www.cu-ads.com $\quad 1.866 .362 .3331$

\section{Health Science Bookstore}

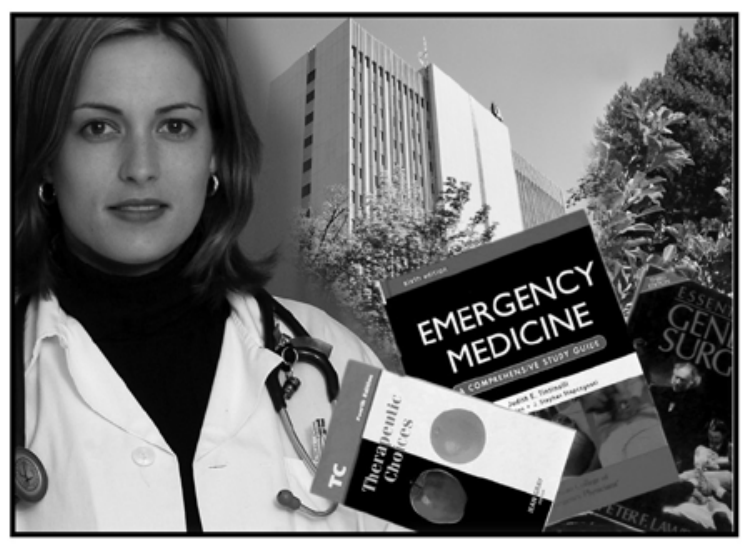

\section{Service, Selection \& Satisfaction}

Let us be your source for Medical Reference Books
Visit us at:

Carleton Campus Bookstore 5981 University Avenue Dalhousie Dentistry Building Tel: 902.494 .6701

Email: bookstore@dal.ca
DALHOUSIE UNIVERS ITY

BOOKSTORES www.dal.ca/bookstore 